\title{
The management of newly identified asthma in primary care in England
}

\author{
Sarah M Dennis, John F Price, Madge R Vickers, Chris D Frost, Mark L Levy, Peter J Barnes
}

\author{
Abstract \\ Aims \\ To establish by case note review how people with newly diagnosed \\ asthma were treated in general practice. \\ Methods \\ A retrospective cross-sectional survey was carried out in twelve \\ general practices from the MRC General Practice Research \\ Framework. Children between their 3rd and 8th birthdays and adults \\ 16 years and over were identified with newly diagnosed or treated \\ asthma from computer records with further details obtained from a \\ case record search. The main outcome measure was the time of \\ recorded asthma diagnosis and the time of first prescriptions for \\ inhaled corticosteroids.

\section{Results} \\ For $41 \%$ of children and $53 \%$ of adults with a diagnosis of asthma \\ and inhaled corticosteroids, inhaled corticosteroids were prescribed \\ before or on the same day as the diagnosis of asthma was recorded. \\ Diagnosis tended to be made on the basis of a patient's medical \\ history with fewer than $20 \%$ of patients having results of any tests
}

recorded in their medical notes. The time from first respiratory consultation to inhaled corticosteroid prescription was statistically significantly shorter in those children for whom a diagnosis of asthma was recorded $(\mathrm{p}=0.038)$ compared to those children without a recorded diagnosis of asthma.

\section{Conclusions}

Inhaled corticosteroids are frequently prescribed before a diagnosis of asthma is recorded. A diagnostic label of asthma in children significantly reduces the length of time from the date of first respiratory consultation to inhaled corticosteroid prescription. If inhaled corticosteroids are to be prescribed early there must be an improvement in the diagnosis of asthma in primary care, including the recording of results in patient's medical notes.

\section{Keywords}

Newly diagnosed asthma, general practice, case note review.

\section{Introduction}

Recent international guidelines for asthma management recommended that inhaled corticosteroids should be a treatment option in adults and children with mild persistent asthma. The definition of mild persistent asthma included a requirement for symptomatic treatment almost daily and implied a 1-3 month period of assessment before initiating anti-inflammatory therapy (Step 2). ${ }^{1}$ The British Thoracic Society Guidelines are similar but suggest an inhaled ß2-agonist requirement of more than once daily before starting inhaled corticosteroids and they state that correct diagnosis is essential to ensure that patients are receiving the most appropriate treatment. ${ }^{2}$ Some have interpreted the guidelines by suggesting that in order to prevent the damage caused by inflammation, inhaled corticosteroids should be started as early as possible. ${ }^{3}$ A feasibility study for a large randomised controlled trial to assess the risks and benefits of early use of inhaled corticosteroids in newly diagnosed asthma had been funded by the NHS R \& D Health Technology Assessment Programme. Recruitment to the trial was slow and now it is unlikely that such a trial could be successfully carried out in general practice in the United Kingdom.

There is still uncertainty regarding the safety of long term inhaled corticosteroids in the management of early asthma, in particular the effects on growth in children. A systematic review reported that moderate doses of inhaled corticosteroids caused a reduction in the linear growth velocity; ${ }^{4,5}$ the effect was less with fluticasone.

We have reviewed the current management of newly identified asthma in adults and children in twelve general practices in England. The review was conducted as part of a feasibility study for a randomised controlled trial of the early use of inhaled corticosteroids in asthma. Recruitment to the trial was slow and this review was carried out to ascertain how these patients were managed in order to understand the reason for this.

\section{Methods}

Twelve practices from the Medical Research Council General Practice Research Framework (GPRF), a network of over 1000 general practices throughout the United Kingdom, took part in the case note review. The twelve practices provided access to notes of over 140000 patients. Four practices completed the paediatric review only, two the adult review only and six completed both the adult and the paediatric review. The practices had previously taken part in a feasibility study for a randomised controlled trial of inhaled corticosteroids in the treatment of newly diagnosed asthma and their decision to take part in this study was dependent on their ability to be able to perform the computer searches. The practices were large with list sizes over 10000 patients, all employed nurses with accredited asthma training and ran asthma clinics. The practice nurses were all experienced in medical research and had received detailed instructions on how to carry out the computer searches and complete the questionnaire.

Children between their third and eighth birthdays and adults sixteen years and over were identified from the practice age sex registers. These age groups were chosen because they were the age ranges used in the feasibility study and we wanted to know how they were managed in primary care and why they were not eligible for the feasibility study. A search was made of the computer prescription records of those patients to identify those receiving, i) a first $\beta 2$-agonist 


\section{Not to be reproduced without the permission of the Primary Care Respiratory Journal}

prescription, ii) a first inhaled corticosteroids (ICS) prescription, iii) a first sodium cromoglycate prescription and iv) a first label of asthma occurring between 1 September 1996 and 1 July 1997. Patients were excluded if they had a diagnosis of respiratory disease other than asthma recorded in their notes. For every eligible patient identified the research nurse completed a brief anonymised questionnaire using the medical notes to ascertain the date of the first recorded respiratory consultation for any respiratory condition and the total number of respiratory consultations, the date of asthma diagnosis, the dates of first asthma prescriptions and details of the drugs prescribed.

Evidence from previous epidemiological studies suggested that three to four adults and three to four children would be newly identified as asthmatic per 2000 list size per year. ${ }^{6,7}$. On the basis of this we expected the practices to identify 166 children and 131 adults during the study period.

All data were analysed using Stata 6 statistical package.

\section{Results}

From total available lists of 102,900 children and 92,000 adults, 161 children and 143 adults were identified of as being prescribed anti-asthma medication in the study period. Assuming that those patients prescribed anti-asthma medication were asthmatic, these numbers are close to the expected number of people newly diagnosed as asthmatic. Of these $118(73 \%)$ and $121(85 \%)$ respectively had a 'diagnosis' of asthma recorded in their notes.

Figures 1 and 2 detail the management of those patients identified by the review. Of the patients with a recorded diagnosis of asthma approximately half of the patients, $56 \%(66 / 118)$ of children and $45 \%$ $(54 / 121)$ of adults, started some form of anti-asthma therapy before a diagnosis of asthma was recorded. Of those patients with a recorded diagnosis of asthma who were also prescribed inhaled corticosteroids (shown in bold shading in the figures), $11 \%(9 / 81)$ of the children and $14 \%(12 / 88)$ of the adults started inhaled corticosteroids before the diagnosis while $30 \%$ $(24 / 81)$ and $40 \%(35 / 88)$ respectively started on the same day as the diagnosis was recorded. In a further $15 \%(12 / 81)$ of children and $6 \%(7 / 88)$ of adults the relative timing of diagnosis and start of inhaled corticosteroids could not be determined. Of those patients who started inhaled corticosteroids after a diagnosis of asthma was recorded, children did so in a median time of 28 weeks and adults in a median time of 8 weeks. Only $14 \%(16 / 118)$ children and $18 \%$ $(21 / 121)$ of adults with a recorded diagnosis of asthma had the results of any diagnostic test recorded in their notes. This decreased to 5\% (2/43) and 5\% (1/22) respectively in those patients without a recorded diagnosis of asthma.

The time from first respiratory consultation to the start of inhaled corticosteroid treatment was significantly shorter in children with a diagnosis of asthma recorded at any time $(\mathrm{N}=80$, median 183 weeks) compared to those children without such a diagnosis of asthma recorded $(\mathrm{N}=9$, median $=243$ weeks) (Wilcoxon rank sum test $\mathrm{p}=0.038$ ).

\section{Discussion}

Our survey indicates that inhaled corticosteroids were often prescribed without confirmation of the diagnosis of asthma. The finding that children with a diagnosis of asthma tended to be prescribed inhaled corticosteroids sooner than those without a diagnosis is consistent with previous studies. ${ }^{8,9}$

The BTS/SIGN British Guideline on the Management of Asthma (Thorax in press) stress the importance of making and recording a diagnosis of asthma to ensure that the most appropriate treatment is prescribed. The objective tests recommended include diurnal variation, response to a trial of treatment or trigger such as exercise. In this review less than $20 \%$ of patients with

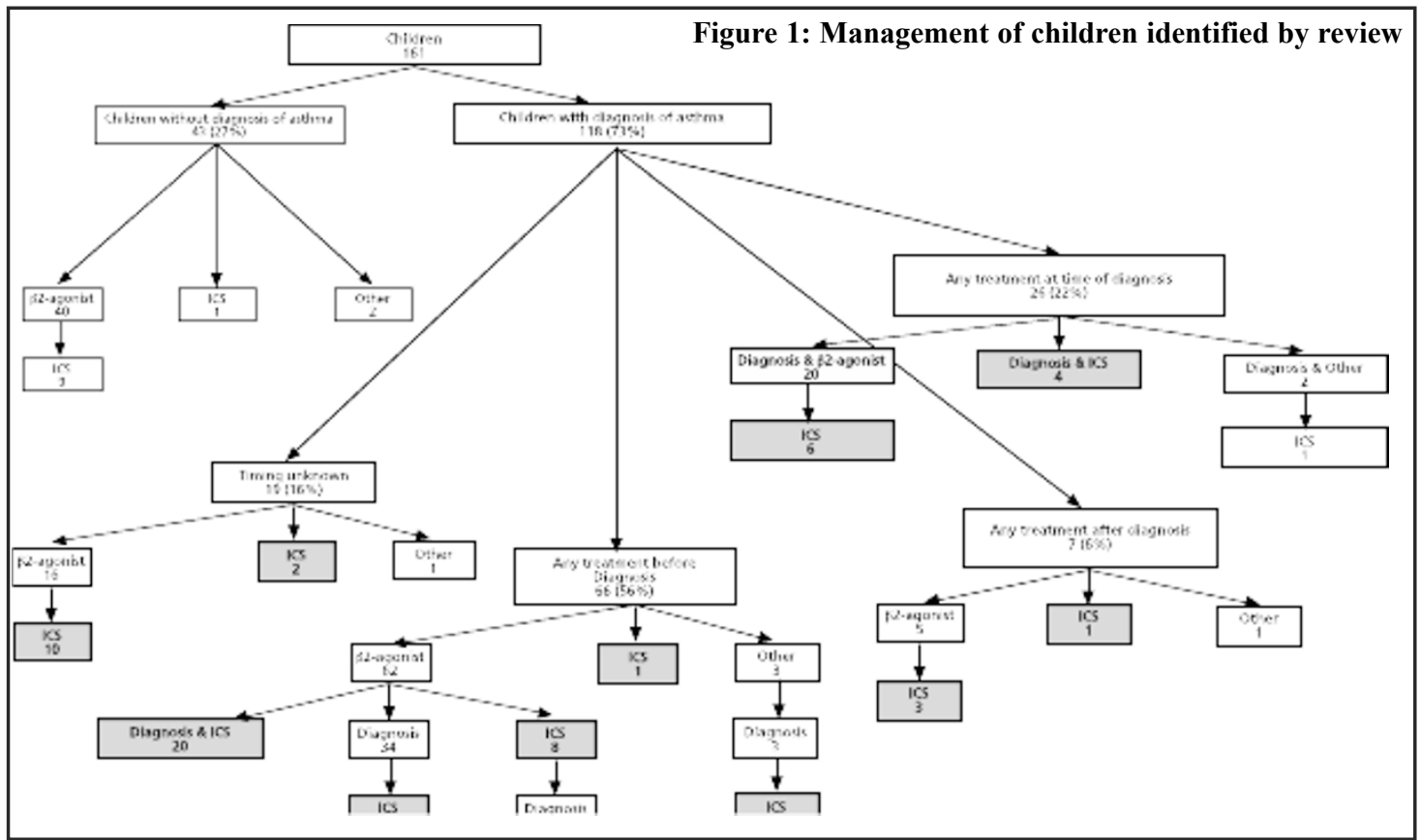

Sarah M Dennis

MRC General Practice Research Framework, University College, London

\section{John F Price}

Guy's, King's and St Thomas' School of Medicine, London.

\section{Madge R Vickers} MRC General Practice Research Framework, University College, London

\section{Chris D Frost}

Medical Statistics Unit, London School of Hygiene and Tropical Medicine

Mark L Levy

Kenton Bridge Medical Centre, Harrow, Middlesex.

\section{Peter J Barnes}

National Heart and Lung Institute, Imperial College School of Medicine, London.

For the Therapy

Working Group of the National Asthma Task Force and the MRC General Practice Research Framework.

Correspondence to:

Dr M R Vickers

MRC General Practice

Research Framework at the MRC Clinical Trials Unit

Stephenson House 158-160 North Gower Street

London NW1 2ND

Tel: +44(0)20 76704851

Fax: +44(0)20 76704890

Email

m.vickers@gprf.mrc.ac.uk

Date submitted: 09/10/02

Date Accepted: 14/11/02

Prim Care Resp J 2002;

11(4): $120-122$ 


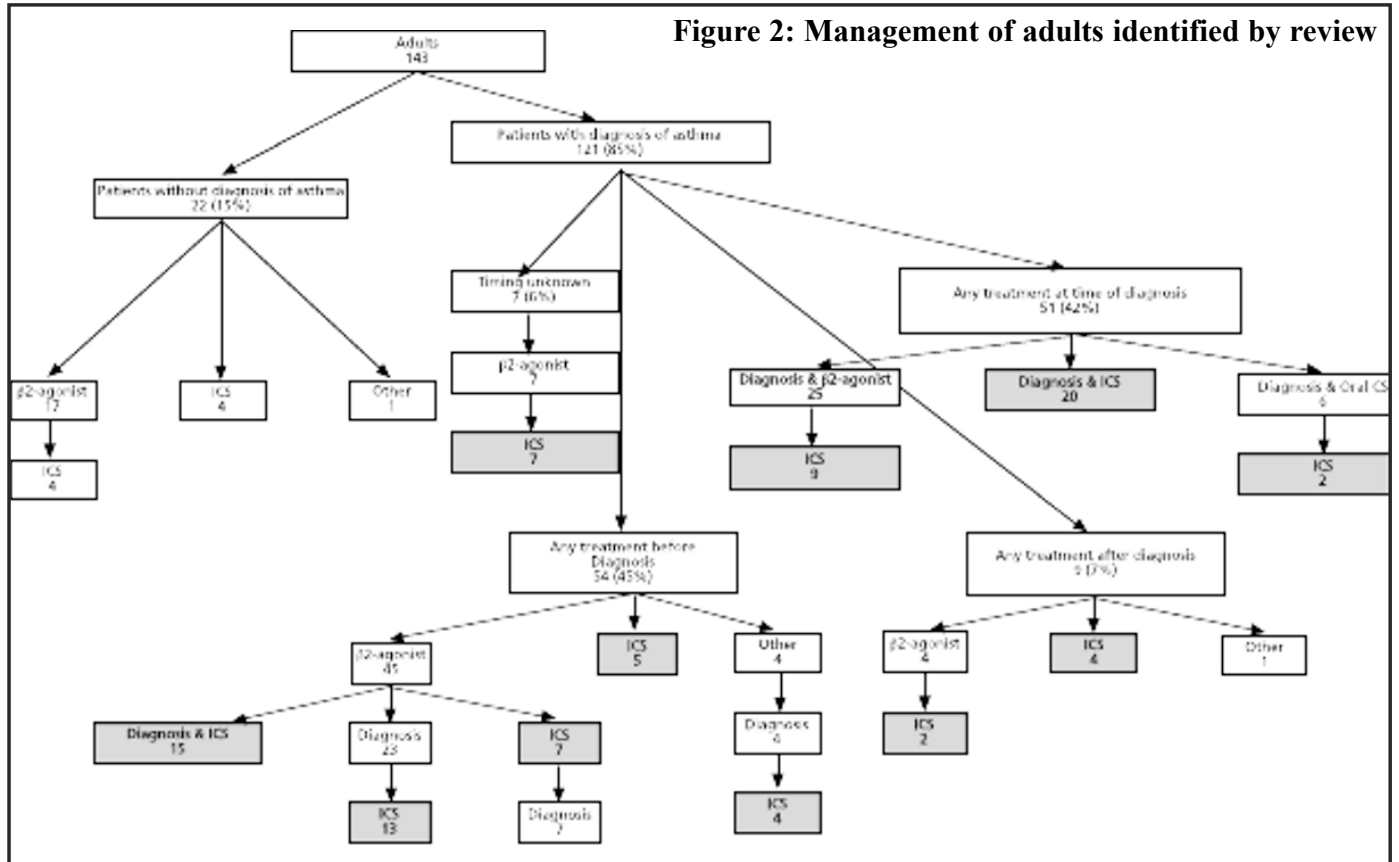

drugs on growth and final height. ${ }^{4}$ The results of this review highlight the problems of trying to conduct such a study in the United Kingdom. Until such studies have been successfully completed perhaps we should be encouraging general practitioners to be more thorough in their diagnosis of asthma before prescribing inhaled corticosteroids and this is reflected in the recommendations in the BTS/SIGN British Guideline on the Management of Asthma (Thorax in press).

Preliminary results presented at the British Thoracic Society Winter Meeting 1997, London.

\section{Acknowledgements}

MRC Epidemiology and Medical Care Unit -

T.W. Meade, P. Brennan,

J.A. Martin, N. M. Fasey, L. Letley and administrative staff.

Participating general practitioners -

J. Buchanan, J. Desveux, P. Ellis, A. Gilmore, P. Goozee, C. Hand, P. Hardy, J. Justice, M. Kennedy, M. Leci, G. Oliver, R. Vohrah.

Research nurses -

A. Allingham, R. Clynes, R. Duffield, L. Dufloux, J. Farmer, A. Hall, L. Hand, J. Houlston, K. Hudson,

E. Marshall, G. Pearson, S. Peck.

MRC regional training nurses -

F. Symes, A. Williams, J. Elwood, P. Allen, A. Hall, L, Hand, E. Marshall. a recorded diagnosis of asthma had the results of any diagnostic lung function tests documented in their notes and this proportion was even less in those patients treated with anti - asthma medication but without a recorded diagnosis of asthma. Furthermore, half of the patients with a diagnosis of asthma started inhaled corticosteroids before or at the same time as the diagnosis was recorded not after a one to three month assessment period as recommended. ${ }^{1}$

The main limitation of this review approach was that we did not attempt to collect information about the severity of the disease and therefore we were not able to comment on the appropriateness of the level of treatment prescribed to the patients. In addition the practices taking part in this review may have been somewhat atypical because of their interest in asthma and research although they had been recruited to the feasibility study for a randomised controlled trial and were expected to identify newly diagnosed or treated asthmatics.

This review has shown that asthma diagnosis often follows the introduction of treatment including inhaled corticosteroids. The use of inhaled corticosteroids did not appear to be preceded by formal assessment of symptom frequency and bronchodilator use and the results documented in the patient's notes.

Nevertheless, there was still a median delay of 3.3 years from the first respiratory consultation to the start of inhaled corticosteroids in children and this was even longer when a diagnosis of asthma was not recorded in the notes. Our study highlights the need for further education about the management of asthma in general practice and shows that inhaled corticosteroids may be started too early in some patients.

There is still a need for randomised controlled trials to assess the risks and benefits of early introduction of inhaled corticosteroids especially in children where there is conflicting evidence as to the effects of these

\section{References}

1. Global Strategy for Asthma Management and Prevention. NHLBI / WHO Workshop Report. 1995 National Heart, Lung and Blood Institute Publication Number 953659.

2. The British Thoracic Society, The National Asthma Campaign, The Royal College of Physicians of London in association with the General Practitioner in Asthma Group, the British Association of Accident and Emergency Medicine, and the British Paediatric Respiratory Society and the Royal College of Paediatrics. The British Guidelines on Asthma Management. 1995 Review and Position Statement. Thorax 1997;52(Supplement 1):S1-S21.

3. Strub G, Rudolf M. Should steroids be the first line treatment for asthma? BMJ 2000;320:47-9.

4. Sharek PJ, Bergman DA. The effect of inhaled steroids on the linear growth of children with asthma: a meta - analysis. Pediatrics 2000;106 (1):1-4 http://www.paediatrics.org/cgi/content/full/106/1/e8. 5. Sharek PJ, Bergman DA, Ducharne F.

Beclomethasone for asthma in children: effects on linear growth (Cochrane Review). In: The Cochrane Library, 1, 2002. Oxford: Update Software. 6. Burney PGJ. Epidemiology. Br Med Bull 1992;48:10-22.

7. Anderson HR, Pottier AC, Strachan DP. Asthma from birth to age 25: incidence and relation to prior and concurrent atopic disease. Thorax 1992; 47(7):537-42.

8. Anderson HR, Bailey PA, Cooper JS, Palmer JC, West S. Influence of morbidity illness label and social, family and health service factors on drug treatment of childhood asthma. Lancet 1981;2:103032.

9.Levy M, Bell L. General practice audit of asthma in childhood. BMJ 1984;289:1115-1116. 